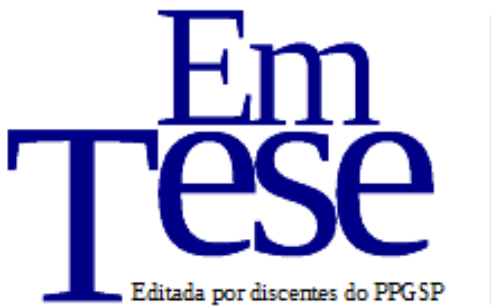

V. 15, n. 2 p. 01, Julho, 2018.

DOI: http://dx.doi.org/10.5007/1806-5023.2018v15n2p69

\title{
Das dicotomias às interdependências: aspectos teórico-metodológicos do pensamento de Norbert Elias ${ }^{1}$
}

\author{
Ana Maria Bourguignon ${ }^{2}$ \\ Dircéia Moreira $^{3}$
}

\begin{abstract}
Resumo: Destacam-se nesse texto as contribuições de Norbert Elias para a compreensão da sociedade e dos indivíduos no contexto interdisciplinar das Ciências Sociais. A ênfase recai nos aspectos teórico-metodológicos, com vistas a responder as concepções de conhecimento, subjetividade, objetividade, verdade e história para o autor. Partindo da problemática construtivista, são apresentados conceitos-chave de Elias como interdependência, figuração, sociogênese, psicogênese, habitus, poder e história. Resulta da abordagem a ênfase na superação da dicotomia indivíduo/sociedade, o que atravessa o projeto científico e político do autor em tela.
\end{abstract}

Palavras-chave: Norbert Elias; Epistemologia; Ciências Sociais.

\section{De las dicotomias a las interdependencias: aspectos teórico-metodológicos del pensamiento de Norbert Elias}

Resumen: Se destacan en este texto las contribuciones de Norbert Elias a la comprensión de la sociedad y de los individuos en el contexto interdisciplinario de las Ciencias Sociales. El énfasis recae en los aspectos teóricometodológicos, con miras a responder a las concepciones de conocimiento, subjetividad, objetividad, verdad e historia para el autor. A partir de la problemática constructivista, se presentan conceptos clave de Elias como interdependencia, figuración, sociogénesis, psicogénesis, habitus, poder e historia. En el abordaje se pone énfasis en la superación de la dicotomía individuo / sociedad, lo que atraviesa el proyecto científico y político del autor en pantalla.

Palabras clave: Norbert Elias; Epistemología; Ciencias Sociales.

\section{From dicotomies to interdependencies: theoretical-methodological aspects of Norbert Elias's thoughts}

\begin{abstract}
This text highlights the contributions of Norbert Elias to the understanding of society and individuals in the interdisciplinary context of the Social Sciences. The emphasis is on the theoretical-methodological aspects, with a view to answering the conceptions of knowledge, subjectivity, objectivity, truth and history for the author. Starting from the constructivist problematic, key concepts of Elias are presented as interdependence, figuration, sociogenesis, psychogenesis, habitus, power and history. The emphasis is on the overcoming of the individual / society dichotomy, which crosses the scientific and political project of the author on screen.
\end{abstract}

Keywords: Norbert Elias; Epistemology; Social Sciences.

\footnotetext{
1 Esta obra está licenciada com uma Licença Creative Commons Atribuição 4.0 Internacional.

${ }^{2}$ Doutoranda do Programa de Pós-Graduação em Ciências Sociais Aplicadas da Universidade Estadual de Ponta Grossa, Mestre em Sociologia Política pela Universidade Federal de Santa Catarina, Graduada em Direito pela Faculdade Campo Real. Bolsista CAPES. E-mail: anamariabourg@ gmail.com

${ }^{3}$ Doutora em Direito pela Pontifícia Universidade Católica de São Paulo. Atualmente é docente do Programa de Pós-Graduação em Ciências Sociais Aplicadas e do curso de graduação em Direito da Universidade Estadual de Ponta Grossa. E-mail: dirceia@ dirceiam.com.br
} 
Há uma clara ligação entre os abismos que se abrem entre indivíduo e sociedade, ora aqui, ora ali, em nossas estruturas de pensamento, $e$ as contradições entre exigências sociais e necessidades individuais que são um traço permanente de nossa vida.

Norbert Elias (1994, p. 15)

\section{Introdução}

Neste estudo sobre o pensamento de Norbert Elias, procuramos demarcar as principais ideias do autor, sua concepção de ciência, os critérios de objetividade/subjetividade presentes em sua teoria social e a problematização da realidade por ele pesquisada. Compartilhamos da afirmação de Sell (2002) de que uma obra clássica é sempre uma obra atual. Dentre as várias qualidades que tornam o pensamento de Elias atual, Ribeiro (1990; 1993) e Waizbort (1999a, p. 13) mencionam a construção de um modelo teórico que se propõe interdisciplinar, porque faz uma crítica constante à barreira das especialidades dos conhecimentos no campo das ciências humanas. Outra qualidade destacada pelos intérpretes é a atenção que Elias dirige a assuntos considerados menores ao seu tempo pela historiografia e sociologia dominantes, contribuindo para "[...] a validação e valorização de campos e objetos empíricos ainda pouco explorados", conforme Waizbort (1999a, p. 15).

De acordo com Sell (2002, p. 18) há, em geral, duas formas de analisar autores clássicos. A de caráter histórico considera a construção interna da produção intelectual, seguindo a cronologia da teoria. A de caráter sistemático procura elaborar uma síntese da teoria do autor. Optamos, aqui, por realizar um estudo de caráter sistemático, mas que não pretende esgotar todo o potencial analítico do modelo teórico do autor, nem a análise de todas as suas obras. Essa opção se justifica pela pretensão didática de compreender as principais contribuições de Elias para o estudo do conhecimento científico em ciências sociais, isto é, a epistemologia.

A epistemologia é um ramo da teoria do conhecimento dedicada ao estudo dos fundamentos filosóficos do conhecimento científico (SELL, 2002, p. 42); e a concepção que cada autor tem sobre como ocorre o processo de conhecimento impacta diretamente sobre o modo como cada um vai conceber a relação indivíduo-sociedade, bem como o tipo de método científico considerado mais adequado para as ciências sociais (SELL, 2002, p. 42). Nesta perspectiva, Sell (2002, p. 18) propõe três dimensões de análise de autores considerados clássicos: 1) contribuições teórico-metodológicas, com intuito de definir o aparato de conceito e teorias para a interpretação da realidade social; 2) interpretações a respeito do surgimento e 
do caráter da sociedade moderna; 3) projeto político subjacente à teoria do autor, isto é, seus posicionamentos políticos perante a realidade social. A ênfase neste artigo será para a primeira das três dimensões, ainda que aspectos das outras duas se façam presentes.

A partir dessa perspectiva, tomamos as questões elaboradas por Sell (2002, p. 45) para uma aproximação dos aspectos teórico-metodológicos presentes em um sistema conceitual, quais sejam: "o que uma ciência estuda", "quais as fronteiras entre natureza, indivíduo e sociedade", "quais elementos definem o que chamamos de social"; "como esta ciência pode explicar o conjunto da realidade que the foi determinado"? Estas questões balizam a análise do eixo teórico-analítico que tentaremos empreender. Assim, nos propomos o desafio de identificar como Elias propõe superar as dicotomias presentes nas perspectivas clássicas das ciências sociais - indivíduo/sociedade, materialismo/idealismo, objetividade/subjetividade, voluntarismo/determinismo (CORCUFF, 2001, p. 11; KIRSCHNER, 1999, p. 31). E, a partir dessa identificação, procuraremos compreender os principais conceitos formadores de seu modelo teórico.

$\mathrm{O}$ artigo está dividido em duas partes. $\mathrm{Na}$ primeira, apresentamos uma contextualização biográfica, que auxilia na compreensão da obra de Norbert Elias. Na sequência, passamos às contribuições do pensamento eliasiano para as Ciências Sociais, item que comporta dois tópicos: (a) a problemática construtivista e a sociologia processual; e (b) os principais conceitos do autor.

\section{Norbert Elias: um outsider de seu tempo}

Judeu, alemão e sociólogo, três qualificações que caracterizam a trajetória intelectual e pessoal de Norbert Elias (WAIZBORT, 1999a, p. 11). Elias nasceu em 1897, filho único de um casal de judeus pertencente à burguesia de Breslau, cidade que à época estava sob domínio do Império Alemão [desde o fim da segunda guerra a cidade faz parte da Polônia]. Em referência ao lugar e ao contexto onde cresceu, o próprio Elias se define como um outsider. Pois ao mesmo tempo em que se "identificava fortemente com a cultura alemã", afirmando inclusive sentir orgulho de pertencer a esta tradição, tal qual Goethe, Schiller e Kant, fazia parte da comunidade judaica, no momento em que o movimento antissemita crescia na Alemanha (ELIAS, 2001b).

Sua família circulava nos nichos da alta cultura de Breslau, formada pela comunidade judaica, o que garantiu o acesso de Elias aos estudos, ao contato com artes e literatura. Seu pai era um homem de negócios, mas que se ressentia por não ter cursado a universidade e, 
portanto, depositava toda essa expectativa em seu filho único. Sua mãe era responsável pela organização de todos os compromissos sociais da família. Ao se recordar das recepções que sua mãe organizava em casa e das conversas entre seus familiares, Elias conta que não se identificava com aquela vida, que "aquilo não era do seu feitio". Assim manifestou o desejo de ser professor desde tenra idade: "Soube muito cedo o que queria fazer: queria ir para a universidade, queria ensinar e pesquisar" (ELIAS, 2001b).

Demorou muito para que Elias concretizasse esse desejo, conforme Mennell (2011) e Kirschner (1999, p. 27), pois ocupou pela primeira vez o cargo de professor apenas aos cinquenta e nove anos na Universidade de Leicester, Inglaterra. Até chegar lá, percorreu um longo caminho. Serviu durante a primeira guerra em uma unidade do exército que instalava postos telefônicos. Terminada a guerra, ingressou na faculdade de Medicina, chegando a completar o treinamento pré-clínico, e de Filosofia da Universidade de Breslau, onde obteve o título de doutor em Filosofia em 1924. Em Heidelberg, continuou seus estudos, mantendo contato com Alfred Weber e Karl Mannheim. Em 1929 foi com Mannheim para Frankfurt trabalhar como seu assistente de pesquisa, período em que escreveu A sociedade de corte. $\mathrm{O}$ trabalho em Frankfurt foi interrompido pela ascensão do nazismo na Alemanha, forçando-o a procurar exílio primeiro em Paris (onde ficou por dois anos) e depois na Inglaterra, país em que permaneceu por quarenta anos. O Processo Civilizador começou a ser escrito ainda em Paris e levou três anos para ser concluído, sendo publicado em 1939 (ELIAS, 2001b). Em 1954, ao ser admitido na Universidade de Leicester, trabalhou para a instituição do Departamento de Sociologia. Entretanto, conforme Menell (2011), o reconhecimento de sua contribuição para as ciências humanas ocorreu tardiamente, especialmente após a publicação em alemão de $O$ Processo Civilizador em 1969. Também, após a aposentadoria, grande parte de seus livros foram publicados. Elias morreu em 1990, em Amsterdam, Holanda.

\section{Contribuições teórico-metodológicas}

Norbert Elias é considerado autor de uma sociologia própria e precursor de uma abordagem epistemológica distinta que se consubstancia nos "figurational studies”, expressão que designa os estudos interdisciplinares "[...] que descrevem as relações entre poder, comportamento, emoções e conhecimento em uma perspectiva (de maior ou menor grau) de longa duração" (MENNELL, 2011 - tradução livre). Nesse escopo, destacam-se obras que tematizam a longa duração e a temporalidade como O Processo Civilizador, Sobre o Tempo e Os Alemães; bem como estudos de configuração histórica microssociológicas como $A$ 
Sociedade de Corte, Estabelecidos e Outsiders, e Mozart. Sob um viés mais epistemológico e analítico, Elias discute problemas conceituais clássicos da sociologia em livros como $O$ que é a Sociologia, Sociedade dos Indivíduos, Norbert Elias por ele mesmo, Teoria Simbólica, Envolvimento e Alienação. A seguir, situamos o pensamento de Norbert Elias na chamada problemática construtivista, delineamos alguns contornos de sua sociologia processual e definimos seus principais conceitos.

\section{Problemática Construtivista e Sociologia Processual}

Para situar o horizonte epistemológico de Elias, é necessário compreender o esforço do autor em construir um sistema que ultrapasse o pensamento binário que faz os sujeitos (inclusive pesquisadores/as) compreenderem a realidade com base em conceitos que ele considera estáticos e antagonistas, tais como "indivíduo e sociedade", "ação e estrutura", "sujeito e objeto", "micro e macro". Superar estas dicotomias está no âmago do que Corcuff (2001, p. 25-32) denomina de problemática construtivista no âmbito das ciências sociais.

\footnotetext{
É um desafio assumido, de diversas maneiras, pelas problemáticas que denominamos de construtivistas e que supõe um deslocamento do próprio objeto da sociologia: nem a sociedade nem os indivíduos, encarados como entidades separadas, mas as relações entre indivíduos (no sentido amplo e não somente as interações face a face), bem como os universos objetivados que eles fabricam e que lhes servem de suportes, enquanto eles são constitutivos ao mesmo tempo dos indivíduos e dos fenômenos sociais (CORCUFF, 2001, p. 24 - grifos do autor).
}

Corcuff (2001, pp. 26-27) alerta que para os/as pesquisadores/as que se defrontam com a problemática construtivista, “[...] as realidades sociais são apreendidas como construções históricas e cotidianas dos atores individuais e coletivos", sendo ao mesmo tempo objetivadas e interiorizadas no processo histórico. O sociólogo chama atenção para a noção de historicidade, comum às abordagens construtivistas, em que as formas sociais resultam de pré-construções herdadas e sobre as quais o indivíduo não tem escolha. Mas que "[...] são reproduzidas, apropriadas, deslocadas e transformadas enquanto outras são inventadas nas práticas e nas interações da vida cotidiana dos atores", abrindo novas possibilidades para o futuro.

Em A Sociedade dos Indivíduos, Norbert Elias (1994, p. 16) critica o isolamento conceitual do indivíduo perante a sociedade nas abordagens clássicas das ciências humanas, afirmando a necessidade de um modelo conceitual que seja capaz de "[...] tornar compreensível, no pensamento, aquilo que vivenciamos diariamente na realidade". Trata-se 
de uma crítica ao modelo inspirado em Comte e Durkheim de que os fatos sociais são coisas e que as estruturas agem coercitivamente sobre os indivíduos de maneira autônoma. Essa caracterização, advinda da separação sujeito-objeto própria do método científico das Ciências Naturais, oferece quatro consequências negativas para o pensamento sociológico: a) a ideia de que o/a pesquisador/a é um observador externo à realidade; b) a concepção de que é possível descrever leis imanentes ou metafísicas que determinariam as práticas dos indivíduos - estes isolados desta estrutura; c) a identificação de tudo o que foge à normalidade das estruturas como anomias; d) a definição aparentemente oposta: que seria possível a existência de um indivíduo isolado, completamente autônomo, a ideia de um homo clausus - seja para sofrer as consequências da estrutura ou para agir independente a ela (ELIAS, 2001, p. 98). Portanto, Elias procura superar a dicotomia entre indivíduo e sociedade - em que algumas abordagens valorizam mais o indivíduo (concebendo-o como totalmente livre) e outras que, ao enfocarem na sociedade, sufocam as possibilidades de ação do indivíduo.

Além de criticar o pensamento dicotômico da realidade, Elias destaca que os conceitos como "homem", "família", "sociedade" são expressos comumente de forma estática, modelar, em forma de quadro. $\mathrm{O}$ autor devota críticas aos conceitos filosóficos imanentes, que revelam algum tipo de essência inalterável e que são transmutadas para reflexões históricas e sociológicas. Norbert Elias argumenta que se perde o potencial de compreensão da realidade quando pensamos os conceitos estaticamente, o que denomina de reducionismo processual. Para isso, constrói um modelo teórico que põe em foco o aspecto dinâmico da realidade, a ideia de processo. Em sua perspectiva não há como desprender do substantivo "sociedade" a noção de "socialização", por exemplo. É por essa razão que o modelo teórico de Elias é denominado de sociologia dos processos, sociologia processual ou figuracional, e considerada uma de suas principais contribuições (WAIZBORT, 1997, pp. 103-104).

A denominação sociologia figuracional advém da ideia defendida por Elias (2006, p. 26) de que as figurações humanas são o campo de investigação da sociologia e, mais amplamente, das ciências sociais. Conforme Elias, o conceito de figuração é um ponto que distingue seu modelo teórico das sociologias de Weber e de Durkheim, porque pressupõe a superação do "tradicional dilema da sociologia: "aqui o indivíduo, ali a sociedade". A sociologia figuracional parte do pressuposto da interdependência fundamental entre os seres humanos.

Seres humanos singulares convivem uns com os outros em figurações determinadas. Os seres humanos singulares se transformam. As figurações que eles formam uns com os outros também se transformam. Mas as transformações dos seres humanos singulares, e as transformações das figurações que eles formam uns com os outros, 
apesar de inseparáveis e entrelaçadas entre si, são transformações em planos diferentes e de tipo diferente (ELIAS, 2006, p. 26-27).

Nesta perspectiva teórica, os problemas de pesquisa no âmbito das ciências sociais possuem um caráter processual, em que se relacionam macro e microdinâmicas observáveis em transformações de longa duração, isto é, períodos não menores que três gerações. Conforme justifica Elias (2006, pp. 27-28), "Processos sociais mais longos permitem reconhecer frequentemente e de modo bastante claro a ruptura de um estágio do processo para outro mediante um decisivo deslocamento de poder". Para se investigar esses fenômenos, a sociologia processual utiliza, como instrumental, pares conceituais opostos, que possibilitam identificar a direção dos processos sociais, tais como: "integração e desintegração, engajamento e distanciamento, civilização e descivilização, ascensão e declínio". Concorrente ao processo de desintegração do feudalismo ocorreu o processo de integração que formata o Estado moderno, como exemplifica Elias (2006, p. 28).

A sociologia de Norbert Elias propõe que processos sociais e ações humanas são inseparáveis, pois assim como cada ser humano nasce em contextos sociais estruturados (a exemplo da língua), as ações humanas acontecem em processos sociais em curso, de modo que uma dimensão (indivíduo) é interdependente em relação a outra (sociedade) e ambas constituem um movimento dinâmico e continuamente em fluxo (ELIAS, 2006, p. 31).

\section{Instrumentos conceituais da teoria social de Norbert Elias}

Norbert Elias construiu um conjunto de ferramentas conceituais para as ciências sociais que visam dar conta de pensar a realidade de forma dinâmica e relacional, dos quais destacamos nesse intento os seguintes conceitos: interdependência, figuração, sociogênese, psicogênese, habitus, margem de ação, poder, distanciamento, engajamento e história.

O conceito de interdependência parte do pressuposto que é impossível pensar em um indivíduo completamente independente. As interdependências advêm de necessidades biológicas (de pais e filhos, por exemplo) e se complexificam na resolução de necessidades socialmente compartilhadas (linguagem, alimentação, vestuário, comportamentos, trabalho, organização do estado, lazer, etc), formando redes de funções interdependentes. A noção de interdependência se refere às relações estabelecidas entre indivíduos que constituem modalidades de estruturação internalizadas, históricas e dinâmicas, que caracterizam uma formação social. Essas formações indicam as regras em que ocorrem as interdependências, o que Elias denomina de figuração ou configuração. Figuração e interdependência constituem 
dois conceitos reflexivos, de modo que mudanças nas relações de interdependência alteram a figuração.

Antes de indicar coerção, Elias prefere a figura do jogo para explicar que as regras de uma determinada figuração só fazem sentido para aqueles que interdependentemente nele atuam. Cabe destacar novamente que as formações sociais para Elias estão temporalmente circunscritas (CHATIER, 2001, p. 10), ou seja, a figuração em que hoje vivemos foi herdada historicamente, entretanto, na dinâmica de relações entre os indivíduos nessa formação social há a possibilidade transformação tanto das interdependências quanto da figuração.

\begin{abstract}
Todas essas funções interdependentes, as de diretor de fábrica ou mecânico, donade-casa, amigo ou pai, são funções que uma pessoa exerce para outras, um indivíduo para outros indivíduos. Mas cada uma dessas funções está relacionada com terceiros; depende das funções deles tanto quanto estes dependem dela. Em virtude dessa inerradicável interdependência das funções individuais, os atos de muitos indivíduos distintos, especialmente numa sociedade tão complexa quanto a nossa, precisam vincular-se ininterruptamente, formando longas cadeias de atos, para que as ações de cada indivíduo cumpram suas finalidades. Assim, cada pessoa singular está realmente presa; está presa por viver em permanente dependência funcional de outras; ela é um elo nas cadeias que ligam outras pessoas, assim como todas as demais, direta ou indiretamente, são elos nas cadeias que a prendem. Essas cadeias não são visíveis e tangíveis, como grilhões de ferro. São mais elásticas, mais variáveis, mais mutáveis, porém não menos reais, e decerto não menos fortes. E é a essa rede de funções que as pessoas desempenham umas em relação a outras, a ela e nada mais, que chamamos "sociedade" (ELIAS, 1994, p. 20).
\end{abstract}

A partir dessa concepção, Elias (2008, p. 14) defende que categorias como família, escola, estado, antes de serem externas às pessoas, são formadas por elas em interação ao mesmo tempo em que as regras dessas figurações são interiorizadas pelo indivíduo. Conforme Chatier (1997, p. 25) as noções de sociogênese e de psicogênese foram criadas por Elias para “[...] proceder ao exame simultâneo da mudança das estruturas psíquicas e das estruturas sociais em seu conjunto", constitui uma abordagem que pretende superar a perspectiva disciplinar que impõe barreiras à possibilidade de analisar aspectos psicológicos e sociais de um mesmo fenômeno. A abordagem sociogenética "[...] visa situar os mecanismos de formação e os princípios de estruturação de uma figuração social dada", e a abordagem psicogenética procura "[...] circunscrever a modelagem e a economia do habitus psíquico engendrado por essa figuração". Mediante a aplicação dessas duas abordagens em O Processo Civilizador, Elias demonstra como ocorreu o processo de transformação social dos costumes, de coerção para autocoerção, isto é, como as proibições na esfera dos costumes que eram exteriores foram interiorizadas pelo indivíduo historicamente no Ocidente (CHATIER, 1997, p. 25). 
Conforme Corcuff (2001, p. 43), as relações de dependência que os indivíduos estabelecem entre si, formando teias de interdependência, geram "constrangimentos exteriores" que contribuem para moldar "as estruturas interiores de suas personalidades", o habitus. Elias (1994, p. 123) define o habitus como “[...] a composição social dos indivíduos, como que constitui o solo de que brotam as características pessoais mediante as quais um indivíduo difere dos outros membros de sua sociedade". "O habitus, é para Norbert Elias, uma 'marca' social sobre a personalidade, um produto das diferentes configurações no interior das quais o indivíduo age" (CORCUFF, 2001, p. 43).

Assim, considerando que o sujeito para Elias está condicionado por estruturas sociais e psíquicas próprias da formação social em que ele vive, mas que nas relações em que esse sujeito estabelece com outros há uma margem de ação com potencial de transformação dessa figuração, é possível compreender a concepção de poder para Elias. Em A Sociedade dos Indivíduos, Elias expressa que o poder designa “[...] a extensão especial da margem individual de ação associada a certas posições sociais, expressão designativa de uma oportunidade social particularmente ampla de influenciar a autorregularão e o destino de outras pessoas." (ELIAS, 1994, p. 42).

Corcuff (2001, pp. 40-41) chama atenção para dois aspectos importantes da teoria eliasiana, as interdependências - relações de dependência que ligam os sujeitos entre si - não são necessariamente conscientes pelos indivíduos, assim como não são necessariamente equilibradas e harmônicas, mas em geral desiguais e marcadas pela dominação e poder. $\mathrm{O}$ poder para Elias é uma característica inerente à concepção de interdependência e, portanto, não é algo que se detém ou possui, mas que se expressa nas relações entre os sujeitos.

Desenhado um panorama conceitual de Norbert Elias, resta esboçarmos como o autor concebe a prática científica nas ciências sociais. Considerando que Elias abandona a dicotomia indivíduo/sociedade, como o autor resolve o problema da objetividade/subjetividade na pesquisa? Em vários trechos de A Sociedade dos Indivíduos, Elias (1994, p. 118) demarca sua posição contrária de aplicação do método e das concepções próprias das ciências da natureza às ciências sociais. Dentre os vários argumentos que utiliza, está a impossibilidade para o/a cientista social ser um observador externo da sociedade, diferentemente do biólogo que pode, por exemplo, estudar externamente uma planta ou um astrofísico que pode observar à distância outros planetas. Outro fator importante de diferenciação, destacado por Corcuff (2001, p. 340), é que a planta ou o planeta são objetos, e os homens e mulheres são sujeitos que manifestam as representações que têm sobre a vida em 
sociedade. Como um crítico da neutralidade ou objetividade científica, Elias propõe ao pesquisador das ciências sociais uma atitude dialética de distanciamento e engajamento ${ }^{4}$.

Distanciamento, pois como em toda ciência, o pesquisador que visa o rigor deve se afastar das idéias preconcebidas (as suas, as dos autores que ele estuda ou mais amplamente, das idéias correntemente compartilhadas no domínio analisado) Engajamento, "pois, se para compreender a estrutura da molécula não se tem a necessidade de saber o que significa se sentir como um dos seus átomos, é porém, indispensável, para compreender o modo de funcionamento dos grupos humanos, ter acesso também do interior à experiência que os homens têm de seu próprio grupo e dos outros grupos" (ibid, p. 29) (CORCUFF, 2001, p. 35 - grifos do autor).

Para ilustrar em que consiste o distanciamento, Elias (1998) utiliza como metáfora a história de dois homens em um barco, repentinamente tragado por um turbilhão nas águas em que se encontrava. Um dos homens desespera-se e, deixando o medo tomar conta de si, acaba afundando junto com o barco. $\mathrm{O}$ outro, que representa a postura do pesquisador no modelo teórico de Elias, controla suas emoções para identificar quais objetos estavam sendo sugados pelo turbilhão. Com essa atitude consegue analisar de forma realista a situação e se salvar, atirando-se do barco e se agarrando ao um barril. O termo distanciamento, portanto, refere-se à atitude de constante autocontrole que cientistas sociais devem ter sobre as projeções e crenças que interferem no trabalho de pesquisa.

$\mathrm{O}$ auto distanciamento permite ao pesquisador/a observar e compreender as relações de interdependência que formam determinada figuração no tempo e no espaço, explicar as motivações de sua gênese e, ao expor, as relações de interdependência, oferecer as possibilidades de alteração da figuração ao longo da história. É desse modo que Elias expõe a constituição e decadência da sociedade de corte, os processos de formação e transformação dos costumes no Ocidente, ou ainda a conformação das microrrelações de um bairro de um subúrbio inglês.

Para realizar empiricamente essas pesquisas, Elias adota o método comparativo, inserido na longa duração histórica, como uma forma de operacionalizar o distanciamento necessário ao processo de pesquisa, fato que ele considera uma de suas mais importantes descobertas: "[...] só se pode descobrir a estrutura das sociedades comparando-as de maneira sistemática" (ELIAS, 2001, p. 66). Chatier (2001, p. 9) complementa que, em A Sociedade de Corte, Elias aplica uma dupla estratégia: o estudo de caso da corte do Rei Luís XIV, e a comparação com a sociedade burguesa dos séculos XIX e XX, como uma forma de contrastar

\footnotetext{
${ }^{4}$ Norbert Elias (1956) dedicou um artigo especificamente sobre a questão da objetividade e subjetividade na prática científica.

${ }^{5}$ Corcuff (2001) cita a obra em francês, cuja primeira edição data de 1983, Engagement et distanciation Contributions à la sociologie de la connaissance. Paris: Fayard, 1993
} 
as formas e os funcionamentos sociais. Constatamos que essa dupla estratégia também é aplicada em $O$ Processo Civilizador, obra na qual o autor explica que o mundo ocidental não se fez somente por um determinismo econômico ou metafisico, ou ainda pela racionalidade de alguns indivíduos, mas que cada indivíduo e todos passaram, paulatinamente, a incorporar práticas subjetivas e objetivas do ser civilizado, com repercussões também nas transformações do sistema político, econômico e social. Além da comparação, a observação participante também é utilizada por Elias em Estabelecidos e Outsiders como um recurso metodológico que propicia o engajamento do/a pesquisador/a.

Por fim, cabe destacar o papel que a temporalidade e a história recebem em seu modelo metodológico e teórico. Elias, ao estudar o processo civilizador, avança na definição de que a complexidade crescente das relações sociais, com o aumento e diversificação das funções que respondem às necessidades, e às necessidades cada vez mais burocratizadas e externas aos sujeitos, há uma modelação do autocontrole. Essas interações entre costumes e regras sociais, já destacadas aqui com os conceitos de psicogênese e sociogênese são elaboradas em uma concepção de sentido na história. Nesse aspecto, há ao menos três consequências do método histórico inovador proposto por Elias: a) a explicação complexa das relações sociais com destaque para objetos pouco valorizados na historiografia até então, como alimentação, lazer, comportamento, etiqueta, moda; b) a compreensão de que os sujeitos não agem racionalmente, que as transformações não são resultado da vontade racional (consciente) dos indivíduos, o que pressupõe que o sentido do processo social difere tanto da ideia de um sentido metafísico da natureza ou do espírito, quanto da racionalidade da mente humana. Quer dizer, o todo é superior e distinto à soma das partes (das ações dos indivíduos), produzindo um sentido (uma ordem) imprevisto e que se volta para a figuração de uma época - bem como de suas possíveis mudanças; c) porém, ainda que não racional, esse processo não é irracional ou acidental, nem descontínuo, se estabelecendo como uma ordenação e com uma direção ${ }^{6}$.

O conhecimento interdisciplinar proposto por Elias busca superar as dicotomias conceituais colocando-se a tarefa de refletir sobre quais as possíveis soluções para as aporias presentes nos projetos para a realização de uma sociedade melhor, mais justa e igualitária. Elias (1994) denuncia os projetos que põem ênfase nas vontades e racionalidades dos indivíduos, em uma liberdade que não considera o todo, quer seja das condições imprevistas

\footnotetext{
${ }^{6}$ Ainda que os processos sociais tenham direções passíveis de serem identificadas e analisadas, a ideia de progresso, como um sentido final do desenvolvimento social é um mito para Elias (2006, p. 32-33). Isso porque os processos sociais são reversíveis, não possuem objetivo nem finalidade, trata-se de um "caminhar não planejado".
} 
que o processo histórico impõe à ação dos indivíduos. Por outro lado, critica os projetos que sobrepujam a sociedade, retirando dos sujeitos o caráter de partícipe dessa mesma sociedade, o que, portanto, impede a compreensão de satisfação das necessidades dos indivíduos como partes constituintes das figurações e de seus potenciais de transformação. O/A pesquisador/a coloca-se como intérprete da realidade social, partícipe na exposição dos processos de interdependência, da história e da explicação das possibilidades de mudança histórica.

Os processos sociais dos quais procuramos construir um modelo, além de nãoplanejados, são inacabados. Ao tratarmos dos percursos que levaram ao presente, ajudamos nossos contemporâneos a se orientar melhor no mundo. Ao mesmo tempo, preparamos o caminho para as gerações futuras, que, auxiliadas pelo trabalho preliminar realizado hoje, poderão adquirir um conhecimento mais amplo e mais seguro que o atual. Nossa tarefa agora é trabalhar em prol da pacificação e da unificação organizada da humanidade (ELIAS, 2006, p. 67).

Por fim, a sociologia processual de Norbert Elias considera o conhecimento como um processo inacabado, mas cuja estrutura conceitual relaciona-se com os modos de conceber e compreender os problemas contemporâneos. Há na sua teoria um compromisso com a construção de um pensamento que possibilite a superação dos abismos que se abrem entre indivíduo e sociedade. Este é o desafio lançado tanto para os sujeitos em seu cotidiano como para os/as cientistas sociais: a superação dos abismos existentes entre os projetos social e individual.

\section{Considerações finais}

A leitura de Norbert Elias é estimulante, porque nos convida a realizar um exercício reflexivo e analítico constante de estranhamento dos conceitos que explicam o modo como vivemos. Reflexivo no sentido que possibilita olharmos para nós mesmos e identificarmos como esses conceitos comumente presentes nas ciências sociais repercutem na formação de nossa própria visão de mundo, e analítico porque nos faz problematizar sistemas teóricos fundantes das ciências humanas e sociais. Com base em nossos estudos, identificamos que uma questão chave da obra de Elias é a crítica à separação conceitual entre indivíduo e sociedade, sujeito e objeto, micro e macro, ação e estrutura. Ele afirma que este "abismo" no campo dos conceitos acarreta importantes repercussões práticas, que levam a tomadas de decisão por um ou por outro polo conceitual. Esse parâmetro de análise teórico-metodológica estende-se para a concepção de história do autor (e do processo de modernização por ele estudado), bem como para as consequências políticas e éticas de seu pensamento. 
Ainda que seja possível criticar o modelo teórico do autor, como o peso excessivo das formações sociais sobre a ação dos indivíduos, o papel lento, gradual e determinante da longa duração e o próprio sentido de desenvolvimento que é imanente em seu método histórico, as contribuições de Elias para a problemática construtivista são reconhecidas por vários autores. Este breve estudo teve como uma de suas tarefas evidenciar o esforço epistemológico de Elias em expor a problemática e sugerir soluções conceituais e metodológicas.

Sob o pensamento de Elias é possível perceber o/a pesquisador/a em uma posição de engajamento e distanciamento, no qual a dicotomia sujeito e objeto, se não perde o sentido, ao menos é atenuado pelo modo construtivista em que os indivíduos formam a sociedade. Conceitos como interdependência e figuração são estabelecidos para superar a dicotomia entre os pensamentos (subjetivo) e a formação social (objetivo), denegando a independência de ambos os polos. A ciência social para Elias exige um arcabouço conceitual específico para pensar a natureza, a mente humana e a formação social. A inovação de objetos empíricos como etiqueta, esporte, lazer, alimentação e relações familiares ganham dimensão relacional com governo, Estado, cultura, classe. Ao refletir sobre o sentido dos sujeitos e a intersubjetividade formadora da sociedade Elias coloca em um patamar diferenciado a produção da vida prática (senso comum) e as construções das verdades que ocorrem na relação entre sujeitos. Uma vez que é no senso comum se expressam, subjetiva e objetivamente, as condições de sociabilidade e os códigos de interpretação do real pelo qual se vale o/a cientista para a produção do conhecimento sobre e do social.

A obra de Norbert Elias permanece instigante e atual. Fenômenos recentes como os processos colonizadores que repercutem fortemente nos países periféricos, como o Brasil, podem ser melhor compreendidos a partir da leitura dos dois tomos de O Processo Civilizador, nos quais Elias explica como a ideia de civilização transformou-se em atributo da sociedade ocidental e expressão da distinção entre nações colonizadoras e colonizadas nos últimos dois ou três séculos. E na obra Os Alemães, na qual Elias explicita as condições históricas e conjunturais que permitiram o Holocausto, em uma convergência de aspectos históricos de longa duração e características interiorizadas pelo povo alemão. Destacamos que essas obras se complementam pois possibilitam uma compreensão de como processos civilizatórios e descivilizatórios podem ocorrer em uma sociedade. Por fim, a obra Estabelecidos e Outsiders, cuja leitura oferece elementos metodológico-conceituais para pensar os processos de integração/desintegração social de migrantes, instiga a reflexão sobre a tensão entre direitos humanos e a capacidade de alteridade dos grupamentos humanos. Estudar esses processos pode contribuir para a elucidação do contexto político atual, que 
aponta para a reversibilidade de conquistas sociais no campo dos direitos humanos, especialmente diante da intensificação dos fluxos migratórios, bem como de práticas governamentais descilivilizatórias, restritivas de direitos e/ou de garantias de condições mínimas de subsistência de povos e populações minoritárias e vulneráveis. 


\section{Referências}

CHATIER, Roger. Prefácio. Formação social e economia psíquica: a sociedade de corte no processo civilizador. In: ELIAS, Norbert. A Sociedade de Corte. Investigação sobre a sociologia da realeza e da aristocracia de corte. Rio de Janeiro: Jorge Zahar, 2001. p. 7-25.

CORCUFF, Philippe. As Novas Sociologias. Bauru-SP: EDUSC, 2001.

ELIAS, Norbert. Problems of Involvement and Detachment. The British Journal of Sociology, v. 7, issue 3, Sep. 1956, p. 226-252. Disponível em:

$<$ http://tucnak.fsv.cuni.cz/ hajek/ModerniSgTeorie/literatura/soliteri/

Problems\%20of\%20Involvement\%20and\%20Detachment.pdf>. Acesso em 23 abr. 2017

ELIAS, Norbert. O Processo Civilizador. Uma história dos costumes. Rio de Janeiro: Jorge Zahar, 1990.

ELIAS, Norbert. O Processo Civilizador. Vol 2: O Estado e a Civilização. Rio de Janeiro: Jorge Zahar, 1993.

ELIAS, Norbert. A sociedade dos indivíduos. Rio de Janeiro: Jorge Zahar, 1994.

ELIAS, Norbert. Os alemães: a luta pelo poder e a evolução do habitus nos séculos XIX e XX. Rio de Janeiro: Jorge Zahar, 1997.

ELIAS, Norbert. Envolvimento e Alienação. Rio de Janeiro: Bertrand Brasil, 1998.

ELIAS, Norbert. Os estabelecidos e os outsiders: sociologia das relações de poder a partir de uma pequena comunidade. Rio de Janeiro: Rio de Janeiro: Jorge Zahar, 2000.

ELIAS, Norbert. A sociedade de corte: investigação sobre a sociologia da realeza e da aristocracia de corte. Rio de Janeiro: Jorge Zahar, 2001a.

ELIAS, Norbert. Norbert Elias por ele mesmo. Rio de Janeiro: Jorge Zahar, 2001b.

ELIAS, Norbert. Escritos \& Ensaios: 1- Estado, processos e opinião pública. Org. de Neiburg e Waizbort. Rio de Janeiro: Jorge Zahar, 2006.

ELIAS, Norbert. Introdução à Sociologia. Lisboa: Edições 70, 2008.

KIRSCHNER, Tereza Cristina. Lembrando Norbert Elias. Textos de História, v. 7, n. 1/2, 1999, p. 27-57. Disponível em: <http://repositorio.unb.br/bitstream/10482/10149/1/ARTIGO_ LembrandoNorbertElias.PDF>. Acesso em 21 abr. 2017.

MENNELL, Stephen. Norbert Elias (1897-1990): A Biographical Sketch. Conference of the British Sociological Association, 6 April 2011. Disponível em:

http://www.norberteliasfoundation.nl/elias/index.php. Acesso em 20 abr. 2017.

MENNELL, Stephen. Figurational Studies: Some Concepts, Principles and Major Research Areas. Amsterdam: Norbert Elias Foundations. Disponível em:

http://www.norberteliasfoundation.nl/network/concepts.php. Acesso em 20 abr. 2017. 
RIBEIRO, Renato J. Apresentação a Norbert Elias. In: ELIAS, Norbert. O Processo

Civilizador. Uma história dos costumes. Rio de Janeiro: Jorge Zahar, 1990. p. 9-12.

RIBEIRO, Renato J. Apresentação: uma ética do sentido. In: ELIAS, Norbert. O Processo Civilizador. Uma história dos costumes. Rio de Janeiro: Jorge Zahar, 1993. p. 9-12.

SELL, Carlos Eduardo. Sociologia Clássica. Itajaí: Univali, 2002.

WAIZBORT, Leopold. Apresentação. In: Waizbort, L. (Org.) Dossiê Norbert Elias. São Paulo: Edusp, 1999. p. 11-15.

WAIZBORT, Leopold. Elias e Simmel. In: Waizbort, L. (Org.) Dossiê Norbert Elias. São Paulo: Edusp, 1999b. p. 89-111.

Recebido em 25-09-2017;

Revisado em 17-04-2018;

Publicação em 15-12-2018. 